\title{
SCOLIOSIS IN PARAPLEGIA
}

\author{
By John A. Odom, JR., M.D. and Courtney W. Brown, M.D. \\ Children's Hospital, Denver, Colorado \\ in conjunction with \\ Robert R. Jackson, M.D., Harry R. Hahn, M.D. and Terry V. Carle, M.D. \\ Craig Rehabilitation Hospital, Englewood, Colorado
}

WITH the increasing instance of excellent medical care, more children with traumatic paraplegia and myelomeningocele with paraplegia live to adulthood. In these two groups of patients there is a high instance of scoliosis, kyphosis and lordosis. Much attention in the past years has been placed on hips and feet but only in the last decade has there been much attention concentrated on the treatment of the spines of these patients. Most of this attention has been toward the patient with a traumatic paraplegia with development of scoliosis.

Some attempts have been made at fusing the scoliotic spine of myelomeningoceles by Harrington Instrumentation but with a rather high instance of complications and failures.

With the event of anterior instrumentation by Dr. Alan Dwyer of Sydney, Australia, the anterior approach to the spine is becoming widely accepted and very successfully used. This is especially valuable in the correction and fusion of the spine with no posterior elements from birth.

\section{MATERIAL FOR STUDY}

Between March of I97I and June of 1973, there have been 26 paraplegics with scoliosis who have been cared for by the authors. All of these patients have either been myelomeningoceles with paraplegia or spinal cord injuries, all of whom have had scoliosis, kyphosis, or severe lordosis.

Eighteen patients were myelodysplastics and eight patients were traumatic paraplegics in childhood who developed scoliosis.

Eight of the myelomeningocele scoliotics have had surgery for correction of their spine problems. Five of the traumatic paraplegics have had spine fusions for their curvatures. One patient, age 44, at the time of his fusion, died I week post-operative from pulmonary insufficiency. All the other patients have done well with few complications.

Seven of the nine scoliotics with myelodysplasia who have not been treated surgically, probably will be treated surgically in the years to come. Three spinal cord injury patients with paraplegia and scoliosis are still being followed, but have not yet developed enough scoliosis to warrant fusion of the spine.

\section{COLLAPSING SPINE}

In two of the patients with spinal cord injuries, a 'spaghetti-like' spine was noted. Each of these patients was actually a $C_{7}$ quad. While their spines collapsed 
in a similar position when they were placed in an erect position, no truly fixed deformity was present in these patients. The primary problem was that they could not sit up straight and get their upper extremities into a position which would make them functional. Attempted bracing as well as support on wheelchairs helped somewhat but did not give the head and arms a stable spine on which to be utilised.

Undoubtedly these spines would have become fixed with deformities with time but both of these patients were fused in their teen years, one by Dwyer Instrumentation from the front and one by Harrington Instrumentation from the back.

The posterior approach with Harrington Instrumentation had no significant complications except for the fact that the patient was kept down for about 6 months before placing him in a wheelchair and getting him up to a useful erect position. The Dwyer Instrumentation was carried out on the other patient in an attempt to get his spine to fuse more rapidly and therefore, get him up sooner. In this patient the cable broke at two places and a posterior instrumentation had to be carried out over these areas at a later date. In idiopathic scoliosis when one does a Dwyer Instrumentation, one can get the patient up easily in 2 weeks and make them ambulatory in a smallplaster jacket. The patient will automatically try to hold himself straight to keep from having pain as he moves and bends. In the paraplegic or quadriplegic, one must use some method of immobilisation even if it is a very stiff corset for several months. Otherwise the patient will move his body enough to dislodge or break the internal fixation.

\section{SCOLIOSIS}

The primary problem in these patients is to get the head balanced over the centre of the pelvis with the shoulders relatively level. Unfortunately one cannot very successfully use a Milwaukee brace in these patients because there is no musculature to work against the brace to straighten the spine. We have had several patients in Milwaukee braces and it works fairly well if the curve is mild and if there is sensation over the crests of the ilia. However, a Milwaukee brace for a patient who already has long leg braces and who is a paraplegic encumbers the patient too much.

It is usually felt that if the curve is progressive at all, that spine fusion should be carried out at a relatively early age rather than wearing a restrictive brace for many years.

With Harrington Instrumentation, one cannot obtain as dramatic a correction as one can with a Dwyer Instrumentation and the immibolisation period for Harrington Instrumentation is longer. However, with Dwyer Instrumentation, one cannot fuse to the sacrum anteriorly. Apparently this has been done in other people's hands but we have not been able to instrument to the sacrum.

Even if one cannot get below L5 with the Dwyer Instrumentation, this is still the surgery of choice in the myelomeningocele, because of the lack of posterior elements. At the second stage, one can later fuse postero-lateral from $\mathrm{L}_{5}$ to the sacrum.

Lordosis has been primarily a problem in the myelomeningocele and has not been a severe problem in the spinal cord injury patients. One can help the lordotic curve some by Harrington Instrumentation but one can dramatically correct 
lordosis by Dwyer Instrumentation. This, of course, is truer in a young spine than in an older spine.

In this series, every patient with lordosis had hip flexion contractures. Hip releases should be carried out in every patient with flexion contracture prior to spine surgery. Recurrence of hip flexion contractures after release and spine fusion has not been noted.

\section{PELVIC OBLIQUITY}

Kyphosis historically has been the worst spine deformity to treat in paraplegics expecially in the myelomeningocele patient. Excision of vertebral bodies and spine fusion is somewhat successful but unless the fusion is carried out well above and below the area of osteotomy, one will get a recurrence at the site of the osteotomy and lordosis above the fusion. It may also be advisable to place a strut-graft anteriorly in these patients.

In a forthcoming paper, we will show our results in posterior Dwyer Instrumentation of the myelomeningocele with complete paraplegia and kyphosis.

\section{DISCUSSION}

It is fairly well accepted that 50 per cent. of the height of the spine is reached by age 2 and 75 per cent. of the height of the spine is reached by age 8. Many orthopaedic surgeons in the past have been reluctant to fuse the paralytic spine until there is rather marked deformity because of the fear of hyperlordosis later in life or shortening the stature of the patient. The instance of lordosis from long spine fusions at an early age is extremely rare. It is better to have a short straight spine than a shorter crooked spine; therefore, it is our strong belief that early spine fusion on the young paralytic spine is indicated.

The indication for spine fusion has only briefly been noted in this paper. The primary reason for fusion is a progressive scoliosis with a curve over $50^{\circ}$ that is not braceable. It is felt that a good surgical team and good post-operative care must be available to carry out this long involved surgery. Excellence in anaesthesia and in the intensive care unit are more important than the abilities of the surgeons.

\section{SUMMARY}

Twenty-six patients with paraplegia and scoliosis have been reviewed. Thirteen of these patients have been instrumented and fused with Harrington or Dwyer Instrumentation. It is felt that Harrington Instrumentation is the surgery of choice in the spinal cord injury patient with scoliosis and Dwyer Instrumentation is the surgery of choice in the myelomeningocele patient without posterior elements and scoliosis. However, one must also consider fusing the myelomeningocele patient from $\mathrm{L}_{4}$ or $\mathrm{L}_{5}$ to the sacrum by the posterior route as well as Dwyer Instrumentation.

Dwyer Instrumentation has also successfully been used in myelomeningoceles with kyphosis by reflecting the cord and meninges and instrumenting the spine with the Dwyer apparatus posteriorly. This will be the subject of a forthcoming paper. 


\section{Discussion}

MR. R. W. JACKSON (Canada). Regarding your question, Mr. Chairman, on prevention. Dr. Odom reports surgically that some four were out-patients. I have recently had occasion to review I063 injuries that we treated from I962 to I972. Thirty-four of these were persons injured under the age of 15 . Without exception those who have pre-pubertal growth have gone into a large $\mathrm{C}$ or $\mathrm{S}$ curve. We have, however, been reasonably successful in preventing this happening until the pubertal age using moulded cyclastic jackets which are well tolerated if holes are punched in for ventilation, and we have had no skin problems to date. But, when they have the pre-pubertal growth we are lost and have either had to do ordinary old-fashioned fusions or hangers. We have been totally unsuccessful in solving this problem.

Mr. T. MCSwEEnEy (G.B.). I would like to make one or two comments on Dr. Odom's paper. Perhaps I wasn't locked on to him throughout the full discussion, and indeed it was an excellent technical paper. I think there are three problems: the meningomycele, which is entirely different from the post-spinal injured child. In the adult, normally there should be no problem. I am sure if you go to see the paraplegic sports tomorrow, you will see deformities just as bad as that with little or no functional disability. Now, as you said Mr. Chairman, the real crux of the matter is the young childthe tetraplegic young child is the biggest problem of all. Now, we have a certain amount of experience on operating on scoliosis at Oswestry, and I think our series is now over 5000 patients. I would be terrified to do a Dwyer fusion on a tetraplegic child, and I don't believe the surgical approach is compatible with the child's survival. I have personally done six Harrington rods, and the children remained in the Intensive Care Unit for 3 weeks later. They were done under the most extreme duress because the child was in respiratory difficulties if it was put in the sitting posture. I know that only six of these patients were post-spinal injury, but I think it would be a great mistake if people left this meeting thinking that there was a solution to the tetraplegic child who develops a scoliosis. It is not a solution-the only thing you can do at the moment is the smallest surgical instrumentation that is compatible with the child's survival.

Mr. E. R. Griffiths (Australia). I would like to make one comment to Dr Odom on the Dwyer procedure. This, as far as I remember from Dwyer, was developed for idiopathic scoliosis initially, not for traumatic paraplegics-and also for collapsing spine in poliomyelitis. A vast number of cases have been done-the original concept was for these cases. Dwyer, as far as I know, has done a few of the traumatic spinal cases. We ourselves have done mainly idiopathic scoliosis and collapsing polio spine, but few of the true traumatic paraplegics. Those we have done of a true collapsing spine are not being held with a Dwyer, the screws have snapped and dispersed, the cable has snapped and we have in all cases had to reinforce them on the concave side by putting in a Harrington rod in certain cases. They have held, but as for the Dwyer itself, either the screw will snap or the cable will snap and disperse. I think it's certainly a major procedure, it takes 6 to 8 hours to do, you must have a healthy fit patient to do it, and I agree with McSweeney, to do a Dwyer procedure on a major high paraplegic or tetraplegic would be very perilous.

Dr. A. A. Siebens (U.S.A.). I thought I would comment on an alternative. It is possible to remove this stress by supporting the individual from his rib cage and actually elevating him so that his lower ribs bear the weight of the body and the lower section of the body acts as a distracting force. Under these circumstances, the curve of the tetraplegic patient or the patient with meningocele is substantially benefited, and it is possible, particularly for the wheelchair-bound individual, to lead a perfectly normal wheelchair life suspended from the upright of the wheelchair. It is also possible for such an individual to be suspended from braces. I draw all this to the attention of this group as a method of eliminating the stress which produces progressive scoliosis in the paralysed child. 
Sir LudWIG GutTManN (G.B.). I am entirely in agreement with the last speaker that prevention is the most important thing and this cannot be started too soon. One gets patients from paediatric and other departments where the care of the children, as far as proper positioning is concerned, has been at fault. A useful point to counteract scoliosis and kyphosis in the early stages can be sport-such as swimming and archery to develop the trunk muscles to keep the spine in a proper position and thus prevent excessive scoliosis.

Furthermore, by systematic hanging, using a corset fixed around the chest and then hanging the patient between parallel bars. With this management we were successful in overcoming contractures of the hip joints resulting in excessive hyperlordosis.

Finally, I feel that every Spinal Unit should have a children's department, because the whole set-up of a Spinal Unit is geared to preserving proper posture of the paralysed, and I am very glad that in this respect there are two spinal units which are doing pioneer work-Dr. Gregg's in Dublin and Professor Paeslack's in Germany.

Dr. J. Odom (U.S.A.). To my knowledge, there are only three of these mistakes with surgery for idiopathic scoliosis that I know of in all parts of the world but there may be more since I last heard. One was caused by Dr. Dwyer making an error when the screw went into the spinal cord in a case of idiopathic scoliosis. Another one was postoperatively, where he probably damaged the vascular supply. The other one was also a technical error. But that is a technical error, and if you know what you are doing that doesn't happen. Maybe somebody has to make a mistake to prevent other people from making them in future. When Harrington rods were first done there was a I per cent. instance of paraplegia due to instrumentation in the first several hundred done in the United States. Now it is quite rare. It has always been very rare in Dwyer's procedure as compared with Harrington's. I think this is a very, very infrequent problem, percentagewise, with the great numbers that have been done. Yet, there have been a rare few and I have one of them on my conscience. Doing a wire procedure as Mr. McSweeney said, in a tetraplegic is a major undertaking. Dr. John Hall in Boston has done about 20 of these and to my knowledge he has not had one death or a major complication. We have done only three or four tetraplegics and had one complication. The operation is a long, complicated procedure, and a major undertaking and it is not something that we do on the spur of the moment. It is well-planned-not perhaps as good as the spaceshot to the moon-but we try very hard, we know exactly what we are doing as we have our team completely knowing what we are doing, we have all the modern technicological equipment and we have an intensive care unit.

As far as methods of preventing, of course prevention is always better than surgery and we did have methods of treating the patients conservatively before, but today, of course, the treatment is primarily surgical. As far as hanging the patient, Hippocrates did this in 800 B.C. and maybe that's the reason we've grown up. 